\title{
An investigation of relation between organizational justice and professional commitment of staff: A case study of public organization in Kermanshah
}

\author{
Mahmoud Malmir ${ }^{a^{*}}$, Mohammad Javad Esfahani ${ }^{\mathrm{b}}$ and Mostafa Emami ${ }^{\mathrm{c}}$
}

\section{H R O N I C L E} \\ Article history: \\ Received January 14, 2013 \\ Received in revised format \\ 18 April 2013 \\ Accepted 20 April 2013 \\ Available online \\ April 212013 \\ Keywords: \\ Organizational justice \\ Procedural justice \\ Interactional justice \\ Distributive justice \\ Professional commitment
}

${ }^{a}$ Assistant Professor of Islamic Azad University, Khorasgan Branch (Esfahan), Khorasgan (Esfahan), Iran

${ }^{b}$ Department of Industrial Engineering, Young Researchers Club, Naragh Branch, Islamic Azad University, Naragh, Iran ${ }^{c}$ Young Researchers Club, Kermanshah Branch, Islamic Azad University, Kermanshah, Iran

\section{A B S T R A C T}

This paper presents an empirical study to investigate the relationship between organizational justice and professional commitment in Kermanshah official organizations. The study uses 20 questions to measure professional commitment from a questionnaire originally developed by Spell et al. (2007) [Spell, C. S., \& Arnold, T. J. (2007). A multi-level analysis of organizational justice climate, structure, and employee mental health. Journal of Management, 33(5), 724751.]. In addition, the study adopts 12 questions from another questionnaire developed by Vallas (1999) [Vallas, S. P. (1999). Rethinking post-Fordism: The meaning of workplace flexibility. Sociological theory, 17(1), 68-101.] to measure organizational justice. Cronbach alpha for organizational justice questionnaire and professional commitment are 0.81 and 0.89 , respectively, which are well above the minimum acceptable level. Based on the results of this survey, there is a positive and meaningful relationship between organizational justice and professional commitment. The implementation of the linear regression analysis also reveals that there is a positive and meaningful relationship between inter-organizational justice and professional commitment. The study performs Freedman test to rank three components of organizational justice and the results indicate that interactional justice maintains the highest level of importance while distributive justice comes last in terms of priority.

\section{Introduction}

Employee commitment plays essential role on long-term success of any organization. Organizational commitment normally depends on various factors such as wages and benefit package, etc. There are literally various studies associated with professional commitments. Armstrong et al. (2007) implemented quality of work life theory and the causal mapping technique to evoke the concepts and linkages of women's cognitions about work-family conflict to understand what contributes to

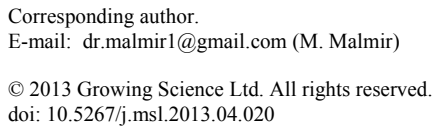


advancement barriers and voluntary turnover of women in information technology (IT). In their survey, the major concepts including managing family responsibilities, Work stress, work schedule flexibility, and job qualities were found to not only influence each other but also were important factors impacting women's advancement opportunities and voluntary turnover. During the past few four decades, there have been tremendous efforts on organizational justice.

Ambrose (2002) performed a literature review on various studies and explained that most studies focused on finding answers for three important questions: (1) Why do people care about justice? (2) What affects justice judgments? and (3) What outcomes are associated with justice judgments? Bakker and Demerouti (2008) provided an overview of the recently introduced concept of work engagement and reported that work engagement could be defined as a state including vigor, dedication, and absorption.

Chan and Wyatt (2007) investigated Quality of Work Life (QWL) in China in terms of how their work lives satisfy eight basic employees' needs and how the satisfaction of each individual's requirements in work life influences employees' job satisfaction, affective commitment, turnover intention, life satisfaction and general well-being. They reported that esteem need satisfaction was the most important item for life satisfaction and turnover intention while four needs including esteem, actualization, economics and family, and health and safety predicted general well-being.

Elias (2006) investigated the impact of professional commitment and anticipatory socialization on accounting students' ethical orientation. He examined professional commitment and anticipatory socialization, operationalized by perception of financial reporting, as possible determinants of Accounting students' ethical perceptions and intentions. He reported that accounting students with higher degrees of professional commitment and higher perception of the importance of financial reporting tend to perceive questionable actions as unethical and less likely to engage in such actions compared with other students with lower commitment and lower perception of financial reporting. Fields and Thacker (1992) investigated the influence of quality of work life (QWL) (Hian \& Einstein, 1990) on company and union commitment. They reported that company commitment increased when participants perceived the QWL effort as successful, but union commitment increased irrespective of the perception of QWL success.

Giffords, E. D. (2003) investigated organizational and professional commitment among public, notfor-profit, and proprietary social service employees. She investigated whether workers' commitment to their organization and commitment to their profession were associated with an organization's auspice, to the nature of their job, and to employees' personal characteristics or not. She found that both organizational and professional commitment were associated with auspice.

Greenberg (2006) performed an investigation on inter-organizational commitment in two hospitals in United States and concluded that the degree of insomnia was substantially lower among nurses whose supervisors were trained in interactional justice, both immediately after training and 6 months later. Hall et al. (2005) performed comprehensive reviews on the literature to detect important antecedents and outcomes of accountants' PC. Harter et al. (2002) examined the relationship at the business-unit level between employee satisfaction-engagement and the business-unit outcomes of customer satisfaction, productivity, profit, employee turnover, and accidents.

Kannan and Pillai (2008) performed an examination on the professional commitment of engineering college teachers. Nabatchi et al. (2007) examined the structure and dimensionality of organizational justice in a workplace mediation setting. They reported that a six-factor model of organizational justice provides the best fit for the data and that factor relationships differ little for employees and supervisors. Poon (2004) examined the moderating impact of emotion perception, a basic component of emotional intelligence, on the relationship between career commitment and career success. According to Poon's survey, emotion perception did not moderate the impacts of career commitment on subjective career success. 
Parker and Kohlmeyer (2005) performed an investigation on organizational justice and turnover in public accounting firms. Raju and Srivastava (1994) investigated various factors contributing to commitment to the teaching profession.

This paper presents an empirical study to investigate the relationship between organizational justice and professional commitment in Kermanshah official organizations. The organization of this paper first presents details of investigation in section, results are then expressed in section 3 and finally concluding remarks are given in the last to summarize the contribution of the paper.

\section{The proposed study}

This paper presents an empirical study to investigate the relationship between organizational justice and professional commitment in Kermanshah official organizations. The study uses 20 questions to measure professional commitment from a questionnaire originally developed by Spell et al. (2007). In addition, the study adopts 12 questions from another questionnaire developed by Vallas (1999) to measure organizational justice. The sample size is calculated using the following formula,

$$
n=\frac{N \times z_{\alpha / 2}^{2} \times p \times q}{\varepsilon^{2} \times(N-1)+z_{\alpha / 2}^{2} \times p \times q},
$$

where $N$ is the population size, $p=1-q$ represents the yes/no categories, $z_{\alpha / 2}$ is CDF of normal distribution and finally $\varepsilon$ is the error term. Since we have $p=0.5, z_{\alpha / 2}=1.96$ and $N=660$, the number of sample size is calculated as $n=98$ and in our study, we have distributed 104 questionnaires among the surveyed people. Cronbach alpha for organizational justice questionnaire and professional commitment are 0.81 and 0.89 , respectively, which are well above the minimum acceptable level.

The proposed study of this paper uses Komolouve-Smirenove test, correlation Spireman test, liner regression test, mean test or T-test and Freidman-test to verfy various hypothese of this study. Table 1 demonstrates the results of our survey on examining the normality based on Komolouve-Smirenove test.

\section{Table 1}

The results of Komolouve-Smirenove test

\begin{tabular}{lcccl}
\hline \multicolumn{1}{c}{ Variable } & Sample number & K-S & Sig percentage & Test result \\
\hline Professional commitment & 104 & 0.993 & 0.278 & Normal distribution \\
\hline Organizational justice & 104 & 0.639 & 0.809 & Normal distribution \\
Distributive justice & 104 & 0.991 & 0.280 & Normal distribution \\
Procedural justice & 104 & 0.833 & 0.491 & Normal distribution \\
Interactional justice & 104 & 0.966 & 0.308 & Normal distribution \\
\hline
\end{tabular}

As we can observe from the results of Table 1, all data are normally distributed and we can use Pearson correlation tests to verify the data.

\section{The results}

The main hypothesis of this survey is associated with the relationship between organizational justice and professional commitment in public organization of Kermanshah. The results of Pearson correlation test between these two variables is equal to 0.482 and it is statistically significance with $\alpha$ $=5 \%$. Therefore, we can conclude that organizational justice can improve professional commitment and if understanding of staff increase can increase loyalty of staff.

\subsection{Testing sub-hypothesis}

There are also three sub-hypotheses associated with this study. 


\subsubsection{The first sub-hypothesis}

There is a meaningful relationship between distributive justice and professional commitment in Kermanshah. Findings from spearman correlation coefficient are that understanding of distributive justice is statistically significance when $\alpha=1 \%$ with correlation coefficient of 0.308 , so it has direct and meaningful relationship with professional commitment. Therefore, we can conclude that if understanding of staff increases, we may expect staff to show more loyalty.

\subsubsection{The second hypothesis}

There is a meaningful relationship between procedural justice and professional commitment in official organization of Kermanshah.

The result of Spearman correlation coefficient is 0.39 and it is statistically significance when $\alpha=1 \%$, which means fullness for procedural justice and correlation coefficient are positively correlated and there is a direct and meaningful with professional commitment of staff. Therefore, we can conclude that if procedural justice increases, loyalty of staff will also increase.

\subsubsection{The third hypothesis}

There is a meaningful relationship between interactional justice and professional commitment of staff in official organization in Kermanshah.

The result of Spearman correlation coefficient is equal to 0.431 , which is statistically significance with $\alpha=1 \%$ and we can conclude that there is a direct and meaningful between interactional justice and professional commitment.

\subsection{The results of regression analysis}

We have also performed a regression analysis between organizational justice and professional commitment. Finding of liner regression between variable of organization justice and professional commitment shows that there is meaningful relationship between organizational justice as an independence variable and professional commitment and it shows that interactional justice could represent $31 \%$ changes in professional commitment.

\subsection{The results of Freedman test}

In order to rank the relative importance of three components of the survey, we may apply Freedman test. Ordering results for the implementation of Friedman test confirm our understanding. Among 3 dimensions of justice, interactional justice has a mean of 3.41 representing the highest rate followed by distributive with 2.95 and procedural score is 3.09 in the second row. Therefore, ordering results for Freidman shows that mean score for professional commitment is 3.60 and mean score for all of dimension are emotional professional commitment (3.64), continuous professional commitment (3.60) and normal professional commitment is (3.56).

In terms of distributive justice in our survey, bonus and fairness of payments and wages received a low rank, which means employees are not satisfied from the benefit package.

In terms of procedural justice index, decision making of managers with regarding satisfaction of beneficial groups gave the lowest scores to them. In interactional justice dimension, two indexes of polite behavior with manager and kind behavior allocate higher scores to themselves. These two indexes among 18 indexes of organizational justice have highest scores, so all of them are above 3. 


\subsection{Results of fitness of justice in organization}

For determining fitness of justice in organization, we use t-test and the amount of P-value is calculated as 0.34 , which is less than $5 \%$. Therefore, our hypothesis based on unfitness of organizational justice score has been rejected and we conclude that understanding of justice in organizations is in good and acceptable condition. In addition, the null hypotheses for fitness of organization on distributive and procedural in organization cannot be rejected when $\alpha=5 \%$.

\subsection{Result of fitness of professional commitment level}

For determining professional commitment level among employees, we use t-test to verify the hypothesis. Results show that P-value for professional commitment and P-value for each of its dimension is less than $5 \%$, so null hypothesis shows unfitness of professional commitment for staff and so it's dimension is rejected, therefor we can say that professional commitment score for staff is in acceptable level.

\section{Conclusion and suggestions}

With regard to aim of research and conclusions and researcher observations we pose some proposal as below:

1. We offer to organization manager to revise payment and wages. Manager must consider that payment and advantage must be according to staff's minimum requirements to increase their motivation to contribute more.

2. Procedures must be for a way of personal bias in management level and they act according to defined rules that are accepted for all. Manager does not have to act based on their attitudes.

3. Maybe there is a problem in an organizational procedure so manager must give a chance to staff to show their disagreements and correct them. Offering systems is proper means for collecting view and offers and doing them.

4. Procedural justice is one of the procedures for improving commitment in organization for decision making. Procedural justice in work environment can give a chance to staff play their roles in organization. Directions, patterns and explicit procedures, freedom of speech and giving view can improve procedural justice in organization. So we propose to managers that with regard to management rules to improve organizational procedures.

5. One of the ways for improving interactional justice is direct and closes relationship and friendly between managers and staffs.

\section{References}

Ambrose, M. L. (2002). Contemporary justice research: A new look at familiar questions. Organizational Behavior and Human Decision Processes, 89(1), 803-812.

Armstrong, D. J., Riemenschneider, C. K., Allen, M. W., \& Reid, M. F. (2007). Advancement, voluntary turnover and women in IT: A cognitive study of work-family conflict. Information \& Management, 44(2), 142-153.

Bakker, A. B., \& Demerouti, E. (2008). Towards a model of work engagement. Career Development International, 13(3), 209-223.

Chan, K. W., \& Wyatt, T. A. (2007). Quality of work life: A study of employees in Shanghai, China. Asia Pacific Business Review, 13(4), 501-517.

Cohen-Charash, Y., \& Spector, P. E. (2001). The role of justice in organizations: A metaanalysis. Organizational Behavior and Human Decision Processes, 86(2), 278-321.

Elias, R. Z. (2006). The impact of professional commitment and anticipatory socialization on accounting students' ethical orientation. Journal of Business Ethics, 68(1), 83-90. 
Fields, M. W., \& Thacker, J. W. (1992). Influence of quality of work life on company and union commitment. Academy of Management Journal, 35(2), 439-450.

Giffords, E. D. (2003). An examination of organizational and professional commitment among public, not-for-profit, and proprietary social service employees. Administration in Social Work, 27(3), 5-23.

Greenberg, J. (2006). Losing sleep over organizational injustice: attenuating insomniac reactions to underpayment inequity with supervisory training in interactional justice. Journal of Applied Psychology, 91(1), 58.

Hall, M., Smith, D., \& Langfield-Smith, K. (2005). Accountants' commitment to their profession: multiple dimensions of professional commitment and opportunities for future research. Behavioral Research in Accounting, 17(1), 89-109.

Harter, J. K., Schmidt, F. L., \& Hayes, T. L. (2002). Business-unit-level relationship between employee satisfaction, employee engagement, and business outcomes: A meta-analysis. Journal of applied psychology, 87(2), 268-279.

Hian, C. C., \& Einstein, W. O. (1990). Quality of Work Life (QWL): What can unions do. SAM Advanced Management Journal, 55(2), 17-22.

Kannan, R., \& Pillai, M. P. (2008). An examination on the professional commitment of engineering college teachers. International Business Management, 2(6), 218-224.

Nabatchi, T., Bingham, L. B., \& Good, D. H. (2007). Organizational justice and workplace mediation: a six-factor model. International Journal of Conflict Management, 18(2), 148-174.

Parker, R. J., \& Kohlmeyer III, J. M. (2005). Organizational justice and turnover in public accounting firms: A research note. Accounting, Organizations and Society, 30(4), 357-369.

Poon, J. M. (2004). Career commitment and career success: moderating role of emotion perception. Career Development International, 9(4), 374-390.

Raju, P. M., \& Srivastava, R. C. (1994). Factors contributing to commitment to the teaching profession. International Journal of Educational Management, 8(5), 7-13.

Spell, C. S., \& Arnold, T. J. (2007). A multi-level analysis of organizational justice climate, structure, and employee mental health. Journal of Management, 33(5), 724-751.

Vallas, S. P. (1999). Rethinking post-Fordism: The meaning of workplace flexibility. Sociological Theory, 17(1), 68-101. 